\title{
Cleaning behaviors in four scorpion species
}

\author{
Jiao GB (1), Zhu MS (1)
}

(1) College of Life Sciences, Hebei University, Baoding, Hebei Province, China.

ABSTRACT: Scorpions rely predominantly on mechanosensory and chemosensory organs to guide their orientation behaviors. Once sensory organs are affected by the presence of dirt such as clay or prey bodily fluid, scorpions may display a cleaning behavior to reduce or eliminate its influence on their sensory capabilities. In the laboratory, cleaning behaviors of two buthid species, Mesobuthus eupeus (Koch, 1839) and Mesobuthus caucasicus (Nordmann, 1840), and one euscorpiid species, Scorpiops luridus Zhu Lourenço \& Qi, 2005 from China, were observed before and after feeding. Moreover, two distinct cleaning behaviors in Scorpiops luridus and three in Heterometrus petersii (Thorell, 1876) (Scorpionidae) were noted for several times during daily activities. Based on these observations, we were able to conclude that different tools and the same tool with diverse applications are used for cleaning the same object in numerous scorpion species.

KEY WORDS: scorpion, cleaning behavior, cleaning means, prey capture, daily activity.

CONFLICTS OF INTEREST: There is no conflict.

FINANCIAL SOURCE: The National Natural Science Foundation of China (grant $\mathrm{n}$. 30670254) and the Doctoral Program Foundation of the Chinese Ministry of Education (grant n. 20050075002).

\section{CORRESPONDENCE TO:}

GUO B. JIAO, 180 Wusi Road, Baoding, Hebei, China. Phone: +86 13613320215. Email: guobinjiao@126.com. 


\section{INTRODUCTION}

Although scorpions are sensitive to light, they are visually weak animals and rely predominantly on two mechanosensory organs - the tarsal slit sensilla on the legs and trichobothria (sensory hairs) on the pedipalps - and one chemosensory organ peg sensilla on the pectines - to guide their orientation behaviors (1). Once the surfaces of these sensory organs are covered in body fluid of injured prey or by other substances such as clay, scorpions may display a cleaning behavior to reduce or eliminate their influence on sensory capabilities.

The scorpion cleaning behavior was first described by Bub and Bowerman (2), who called it "sand thrust", during their study on prey capture by a North American scorpion species, Hadrurus arizonensis Ewing, 1928 (Caraboctonidae). They had observed that the scorpion released one chela from the prey and performed repetitive thrusts into the sandy substrate, while holding the prey with the other chela, either simultaneously or after the sting. Dirt was brushed off from the scorpion chela first by the ipsilateral walking legs and then by the second pair of legs before the animal regrasped the prey. The authors assumed that sand thrusting played a role in cleaning the pedipalps, but did not discuss it any further.

Rein (3) observed another cleaning behavior in two buthid scorpions, Parabuthus leiosoma (Ehrenberg, 1828) and P. pallidus Pocock, 1895. He noticed that scorpions straighten the metasoma and rub the aculeus back and forth on the substrate after a successful sting. In addition, he inferred that sand thrusting was a cleaning behavior with the purpose of removing irritating substances from the pedipalps or metasoma.

Recently, Jiao and Zhu (4) found several cleaning behaviors displayed prior to and after feeding in Heterometrus petersii (Thorell, 1876) (Scorpionidae). This scorpion uses the second pair of walking legs to clean the pectines before hunting and utilizes the first pair to clean chelae during prey capture. After nourishment, Heterometrus also uses chelicerae for combing movable and fixed fingers of chelae.

To the best of our knowledge, cleaning behaviors have been reported only in four out of almost 1,800 scorpion species that have been described (5). Thus, more research on this scorpion behavior could be very valuable. 
The present work reports cleaning behaviors of two buthid species - Mesobuthus eupeus (Koch, 1839) and Mesobuthus caucasicus (Nordmann, 1840) - and one euscorpiid species - Scorpiops luridus Zhu Lourenço \& Qi, 2005 - from China studied in the laboratory. Observations were conducted on 20 adult scorpions (ten males and ten females) from each of the three species under two 40-watt bulbs, which, apparently, did not affect their behaviors $(4,6)$. Additionally, some cleaning behaviors displayed by $S$. luridus and $H$. petersii during daily activities were registered several times through more than two years of non-scheduled observation.

\section{Cleaning behaviors displayed by three scorpions before and after feeding}

Through observations of prey capture by M. eupeus, M. caucasicus and S. luridus, cleaning behaviors were recorded for each species before and after feeding as shown in Table 1. Moreover, the detailed description of each cleaning means is presented.

Table 1. Cleaning behaviors displayed before and after feeding in three scorpion species

\begin{tabular}{|c|c|c|c|c|}
\hline Period & Tool & Object & Means & Species \\
\hline \multirow{6}{*}{$\begin{array}{l}\text { Before } \\
\text { feeding }\end{array}$} & $\begin{array}{l}\text { The first and second pairs of } \\
\text { walking legs }\end{array}$ & Pectines & Rubbing & Scorpiops luridus \\
\hline & $\begin{array}{l}\text { The ipsilateral first walking } \\
\text { leg }\end{array}$ & Chela & Scratching & Scorpiops luridus \\
\hline & \multirow[t]{2}{*}{ Substrate } & \multirow[t]{2}{*}{ Chelae } & \multirow[t]{2}{*}{ Rubbing } & $\begin{array}{c}\text { Mesobuthus } \\
\text { caucasicus }\end{array}$ \\
\hline & & & & Mesobuthus eupeus \\
\hline & \multirow[t]{2}{*}{ Substrate } & \multirow[t]{2}{*}{ Telson } & \multirow[t]{2}{*}{ Rubbing } & $\begin{array}{c}\text { Mesobuthus } \\
\text { caucasicus }\end{array}$ \\
\hline & & & & Mesobuthus eupeus \\
\hline \multirow{3}{*}{$\begin{array}{c}\text { After } \\
\text { feeding }\end{array}$} & \multirow{3}{*}{ Chelicerae } & \multirow{3}{*}{ Pedipalps } & \multirow{3}{*}{ Combing } & Scorpiops luridus \\
\hline & & & & $\begin{array}{c}\text { Mesobuthus } \\
\text { caucasicus }\end{array}$ \\
\hline & & & & Mesobuthus eupeus \\
\hline
\end{tabular}


Only one cleaning means was observed before prey capture in Scorpiops luridus. First, its prosoma was raised slightly, with its third and forth walking legs upholding the body. Subsequently, with outstretched pedipalps in front of the body, Scorpiops curved its metasoma above the back or placed it on the ground. Then, the scorpion used the tarsus of the first and second walking legs to rub its pectines (lamella and pectinal teeth) for about two minutes. Heterometrus petersii displayed a similar cleaning behavior, scratching its pectines (lamella and pectinal teeth) with the claws of the first pair of walking legs (4).

In Scorpiops luridus, during prey capture, if prey bodily fluid adhered to the surface of the chela, the appendage was scratched by the claws of the ipsilateral first walking leg three to five times, while in Mesobuthus caucasicus and M. eupeus it was directly rubbed on the substrate about five times. It is interesting to note that Scorpiops and Mesobuthus employed different means to clean the chela during prey capture.

Scorpiops luridus cleaning behavior observed in the present study was similar to Hadrurus arizonensis comportment described by Bub and Bowerman (2) and Heterometrus petersii behavior reported by Jiao and Zhu (4). Similarly, the cleaning means displayed by Mesobuthus was similar to those of two Parabuthus scorpions previously studied by Rein (3) and a Hadrurus arizonensis observed by Bub and Bowerman (2). Occasionally, Mesobuthus straightened their metasomas and rubbed them on the substrate two or three times after stinging prey, which was also recorded in two Parabuthus scorpions (3).

After feeding, three scorpions presented similar cleaning behaviors. During the cleaning stage, all maintained a posture similar to rest (4). Firstly, the scorpion outstretched its chelicerae and alternately combed the hairs of the chela, then cleaned other pedipalp joints as if combing the hairs on the chela. The interval for cleaning behaviors in each scorpion was more than five minutes, most of which was usually spent cleaning chelae. This type of cleaning behavior was also observed in Heterometrus petersii (4). 


\section{Cleaning behaviors displayed by two scorpions during daily activity}

In addition to observations on the three aforementioned scorpions, another two cleaning behaviors displayed by Scorpiops luridus and Heterometrus petersii during daily activity were analyzed (Table 2). First, the scorpion body, with the tail curved above the back, was supported by its third and forth pair of walking legs and ipsilateral first and second pair of walking legs. Second, each pedipalp joint was rubbed by the tarsus of the ipsilateral first and second pair of walking legs, which did not uphold the body and were occasionally scratched by claws of the first and/or second pair of walking legs. Simultaneously, the hairs on the pedipalp were combed alternately by the chelicerae. The times spent on this cleaning behavior were, respectively, 8 to 15 and 10 to 30 minutes in Scorpiops and Heterometrus.

Moreover, prosoma and mesosoma of scorpions were raised numerous times. When the metasoma was on the ground, with the third and forth pair of walking legs upholding the body, the scorpion's spiracles were rubbed by the tarsus of the first and second pair of walking legs for 2 to 5 minutes and occasionally scratched by the claws of the first and second pair of walking legs three to five times. The time spent on this cleaning behavior was about 2 to 5 minutes in Scorpiops and Heterometrus.

Table 2. Cleaning behaviors displayed during daily activity in Scorpiops luridus and Heterometrus petersii

\begin{tabular}{c|c|c}
\hline Tool & Object & Means \\
\hline The first and second walking legs & Spiracles & Rubbing, scratching \\
\hline The first and second walking legs, chelicerae & Pedipalps & $\begin{array}{c}\text { Combing, rubbing, } \\
\text { scratching }\end{array}$ \\
\hline $\begin{array}{c}\text { The first and second walking legs, chelicerae, } \\
\text { tergum }\end{array}$ & Telson & $\begin{array}{c}\text { Combing, rubbing, } \\
\text { scratching }\end{array}$ \\
\hline
\end{tabular}

Cleaning behavior on telson was only displayed by $H$. petersii

There was also one cleaning behavior presented only by Heterometrus (Table 2), in which the telson was rubbed with its tergum five to ten times and occasionally with the external portion of the chela. Sporadically, the vesicle was scratched by the claws of 
the first and/or second pair of walking legs when it was near the edge of carapace, and the hairs on the vesicle and aculeus were combed alternately by chelicerae three to five times if the telson was in front of the chelicerae. The time spent on this cleaning behavior was about ten minutes.

Through observations, we found that the frequency of cleaning behaviors among scorpion species, or even intraspecies, is remarkable diverse. Some scorpions usually display cleaning behaviors not only after feeding, but also during their daily activity, whereas other scorpions never present them under two conditions.

It is noteworthy that during prey capture, only Hadrurus arizonensis, studied by Bub and Bowerman (2), uses two means to clean its chela, scratching by the ipsilateral pair of walking legs and rubbing it directly into the substrate, while four scorpions in this study just use alternative means. Is this a special behavior only in Hadrurus arizonensis, or other scorpions may also behave this manner on the same object in other cases? Is different cleaning behavior in diverse species related to the variation in life style/habitat/morphology? Due to the lack of observations on more scorpion species, we cannot draw an exact conclusion for these two questions. Thus, further studies on other scorpion species should be conducted in the future.

\section{ACKNOWLEDGEMENTS}

Special thanks are extended to Dr. Rein (Norwegian Institute of Science and Technology, Trondheim, Norway) and Dr. MacDermott (Hebei University) for their helpful comments and suggestions on the manuscript. 


\section{REFERENCES}

1. Brownell PH. Sensory ecology and orientational behaviors. In: Brownell, Polis GA, editors. Scorpion biology and research. New York: Oxford University Press; 2001. p. 159-83.

2. Bub K, Bowerman RF. Prey capture by the scorpion Hadrurus arizonensis Ewing (Scorpiones: Vaejovidae). J Arachnol. 1979;7(1):243-53.

3. Rein JO. Prey capture behavior in the East African scorpions Parabuthus leiosoma (Ehrenberg, 1828) and P. pallidus Pocock, 1895 (Scorpiones: Buthidae). Euscorpius. 2003;6(1):1-8.

4. Jiao GB, Zhu MS. Prey capture behavior in Heterometrus petersii (Thorell, 1876) (Scorpiones :Scorpionidae). Euscorpius. 2009;80(1):1-5.

5. The Scorpion Files [Internet]. Trondheim: Norwegian University of Science and Technology; c2001-2009 [updated 2008 Dec 16; cited 2008 Dec 25]. Available from: http://www.ntnu.no/ub/scorpion-files/.

6. Peretti AV, Carrera P. Female control of mating sequences in the mountain scorpion Zabius fuscus: males do not use coercion as a response to unreceptive females. Anim Behav. 2005;69(2):453-62. 